\title{
An EPQ Model with Power-form Stock Dependent Demand under Inflationary Environment using Genetic Algorithm
}

\author{
Chaman Singh \\ Assistant Professor, Dept. of Mathematics, \\ A.N.D. College (University of Delhi), \\ Delhi-110019
}

\author{
S. R. Singh \\ Reader, Dept. of Mathematics, \\ D.N. (P.G.) College, \\ Meerut, U.P. - 250002
}

\begin{abstract}
In this paper a production inventory model for the newly launched product is developed incorporating the effect of inflation and time value of money. The objective of this study is to find the economic production quantities. It is assumed that demand of the items is displayed stock dependent. Production is stopped when the stock-level reached to level $\mathrm{Q}$ and $\mathrm{Q}_{0}$ is the fixed stock-level. In this paper we discussed the following two situations (I) $\mathrm{Q} \leq \mathrm{Q}_{0}$ and (II) $\mathrm{Q}>\mathrm{Q}_{0}$. Model is formulated to maximize the total profit. A genetic algorithm with varying population size is used to solve the model. In this GA a subset of better children is included with the parent population for next generation and size of this subset is a percentage of the size of its parent set. Numerical example is given to illustrate the model. Sensitivity analysis with respect to various parameters is also presented.
\end{abstract}

Keywords: Genetic Algorithm, Inflation, Stock-dependent demand

\section{INTRODUCTION}

It is well known that the stock level has a motivational effect on the customers in a supermarket; i.e. the demand rate may go up or down if the on-hand inventory level increases or decreases. In corporate world such a situation is known as the stockdependent demand. It generally arises for a consumer-goods type inventory. In this area a large number of mathematical models have been reported in the existing literature. Among them, to get the idea of the trends of recent research, one may refer to the works of Datta et al.(1998), Balki and Benkherouf (2004), Teng and Chang (2005), Wu et al. (2006), Singh et al. (2007), Singh et al. (2010) and Pareek and Rani (2012).

Most of the inventory models unrealistically ignore the influence of inflation. This was due to the belief that inflation would not influence the inventory policy to any significant degree. This belief is unrealistic since the resource of an enterprise is highly correlated to the return on investment. The concept of the inflation should be considered especially for long-term investment and forecasting. Among them, to get the idea of the trends of recent research, one may refer to the works of Lieo et al. (2000), Mehta and Shah (2003), Singh and Singh (2010), Singh and Singh (2011).

In the existing literature most of the research papers have been published assuming that the production rate of a manufacturing system is often assumed to be constant while incorporating the stock-dependent demand, but in fact production rate is a variable under managerial control. Production rate may be influenced due to demand, on hand inventory and launching new competitive product or with the change in customer's preferences.

In this research paper an EPQ model of an item is developed considering the power form stock-dependent demand under inflation. It is assumed that the production rate is demand dependent. Two situations were discussed in this paper (I) $\mathrm{Q} \leq$ Q0 and (II) Q > Q0, where $\mathrm{Q}$ is the stock-level at the time production is stopped and Q0 is the fixed stock-level. Model is formulated to maximize the total profit. A genetic algorithm with varying population size is used to solve the model.

\section{GENETIC ALGORITHM}

Genetic Algorithm is exhaustive search algorithm based on the mechanics of natural selection and genesis (crossover, mutation, etc.). It was developed by Holland, his colleagues and students at the University of Michigan. Because of its generality and other advantages over conventional optimization methods, it has been successfully allied to different decision making problems. To get an idea of recent work on GA, one may refer to the work of Michalewich (1992), Pezzellaa et al. (2008), Golnaz and Reza (2012) and Ramesh and Nanda (2012).

In natural genesis, we know that chromosomes are the main carriers of hereditary factors. At the time of reproduction, crossover and mutation take place among the chromosomes of parents. In this way, hereditary factors of parents are mixed-up and carried over to their offspring. Again, Darwinian principle states that only the fittest animals can survive in nature. So, a pair of parents normally reproduces a better offspring.

The above-mentioned phenomenon is followed to create a genetic algorithm for an optimization problem. Here, potential solutions of the problem are analogous with the chromosomes, and the chromosome of better offspring with the better solution of the problem. Crossover and mutation among a set of potential solutions to get a new set of solutions are made, and it continues until terminating conditions are encountered. Michalewich proposed a genetic algorithm named Contractive Mapping Genetic Algorithm (CMGA) and proved the asymptotic convergence of the algorithm by Banach fixed point theorem. In CMGA, a movement from the old population to a new one takes place only if an average fitness of the new population is better than the fitness of the old one. In the algorithm, pc, pm are probability of crossover and probability of mutation respectively, $\mathrm{T}$ is the generation counter and $\mathrm{P}(\mathrm{T})$ is the population of potential solutions for the generation $\mathrm{T} . \mathrm{M}$ is an iteration counter in each generation to improve $\mathrm{P}(\mathrm{T})$ and $\mathrm{M} 0$ is the upper limit of $\mathrm{M}$. Initialize $(\mathrm{P}(1))$ function generate the initial population $\mathrm{P}(1)$ (initial guess of solution set) at the time of initialization. Objective function value due to each solution is 
taken as fitness of the solution. Evaluate $(\mathrm{P}(\mathrm{T})$ ) function evaluates fitness of each member of $\mathrm{P}(\mathrm{T})$.

\subsection{GA Algorithm:}

1. Set generation counter $T=0$ and maximum generation $M=0$

2. Initialize probability of crossover $p_{\mathrm{c}}$, probability of mutation $p_{\mathrm{m}}$, upper limit of iteration counter $\mathbf{M}_{0}$, population size $N$

3. Initialize $(P(T))$

4. Evaluate $(P(T))$

5. While $\left(M<M_{0}\right)$

6. Select $N$ solutions from $P(T)$ for mating pool using Roulette-Wheel process.

7. Select solutions from $P(T)$, for crossover depending on $p_{\mathrm{c}}$.

8. Make crossover on selected solutions.

9. Select solutions from $P(T)$, for mutation depending on $p_{\mathrm{m}}$.

10. Make mutation on selected solutions for mutation to get population $P_{l}(T)$.

11. Evaluate $\left(P_{l}(T)\right)$

12. Set $M=M+1$

13. If average fitness of $P_{I}(T)>$ average fitness of $P(T)$ then

14. Set $P(T+1)=P_{I}(T)$

15. Set $T=T+1$

16. Set $M=0$

17. End if

18. End While

19. Output: Best solution of $P(T)$

20. End algorithm.

\section{ASSUMPTIONS AND NOTATIONS}

Mathematical model in this paper is developed on the basis of the following assumptions and notation.

3.1. Notations: Following notations have been used in this paper

$\mathrm{c}_{1} \quad$ Holding cost of the inventory item, \$/

per unit / per unit time

Deterioration cost, \$ / per unit

Ordering cost, $\$ /$ per order

Production cost, $\$ /$ per unit

Selling price, $\$ /$ per unit

Deterioration rate

Inflation rate

Discount rate

$=\mathrm{d}-\mathrm{i}$

Maximum inventory level of the ordering cycle

$\mathrm{Q}_{0} \quad$ Fixed inventory level at which the demand becomes constant

$\mathrm{T}$ Length of the production cycle

$\mathrm{I}(\mathrm{t}) \quad$ Inventory level at time $\mathrm{t} \in[0, \mathrm{~T}]$

3.2. Assumptions: Model is developed under the following assumptions

(1) The inventory system involves only one item and the planning horizon is infinite.

(2) Production rate is demand dependent i.e. $P(t)=a D(t)$

(3) The demand rate $\mathrm{D}(\mathrm{t})$ is deterministic and its functional form is given by

$$
\mathrm{D}(\mathrm{t})=\left\{\begin{array}{lc}
\alpha(\mathrm{I}(\mathrm{t}))^{\beta}, & \mathrm{Q}>\mathrm{Q}_{0}, \\
\mathrm{D} & , \quad 0 \leq \mathrm{Q} \leq \mathrm{Q}_{0}
\end{array}\right.
$$

Where $\alpha>0,0<\beta<1, \mathrm{D}=\alpha \mathrm{Q}_{0}{ }^{\beta}$, and both $\alpha$ and $\beta$ are known as scale and shape parameters, respectively.

(4) Shortages are not allowed.

\section{MODEL FORMULATION}

Let the production is stopped when the stock-level reached to level $\mathrm{Q}, \mathrm{Q}_{0}$ is the Constant stock-level. Then there may arise the following two cases

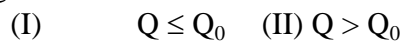

\subsection{Case $I: Q \leq Q_{0}$}

This is the classical EPQ model for deteriorating items with constant demand rate. Production is started at the time $\mathrm{t}=0$, with zero inventory level and stopped at the time $t=T_{1}$ when the inventory level reaches to the level Q. After that inventory level decreases due to the combined effect of demand and deterioration up to the time $\mathrm{T}$, at which inventory level reaches to the zero level. Inventory level at any time can be described by the following differential equation and graphically represented in the figure-1.

$$
\begin{aligned}
& I_{1}^{\prime}(t)+\theta I_{1}(t)=(\mathrm{a}-1) D, \quad 0 \leq t \leq T_{1} \\
& I_{2}^{\prime}(t)+\theta I_{2}(t)=-D, \quad T_{1} \leq t \leq T
\end{aligned}
$$

With the boundary conditions $\mathrm{I}_{1}(0)=0$ and $\mathrm{I}_{2}(\mathrm{~T})=0$. Solution of equation (1) and (2) are as follows

$$
\begin{aligned}
& I_{1}(t)=\frac{(a-1) D}{\theta}\left(1-e^{-\theta t}\right), 0 \leq t \leq T_{1} \\
& I_{2}(t)=\frac{D}{\theta}\left(e^{\theta(T-t)}-1\right), T_{1} \leq t \leq T(4)
\end{aligned}
$$

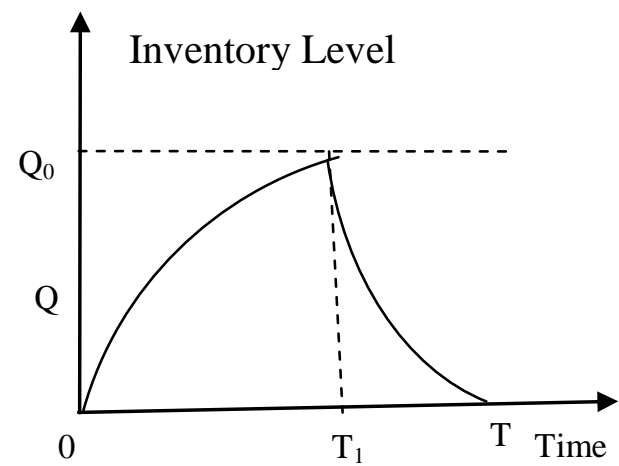

Fig 1: Case I $\left(Q \leq Q_{0}\right)$

From equation (3) and (4), using the condition $\mathrm{I}_{1}\left(\mathrm{~T}_{1}\right)=\mathrm{I}_{2}\left(\mathrm{~T}_{1}\right)$, we have

$\mathrm{T}=\frac{1}{\theta} \ln \left\{\mathrm{a}\left(\mathrm{e}^{\theta \mathrm{T}_{1}}-1\right)+1\right\}$

Maximum inventory level is

$\mathrm{Q}=\mathrm{I}_{1}\left(\mathrm{~T}_{1}\right)=\frac{(\mathrm{a}-1) \mathrm{D}}{\theta}\left(1-\mathrm{e}^{-\theta \mathrm{T}_{1}}\right)$ 
Present worth holding cost of the inventory held is

$$
\mathrm{HC}=\mathrm{c}_{1}\left[\int_{0}^{\mathrm{T}_{1}} \mathrm{I}_{1}(\mathrm{t}) \mathrm{e}^{-\mathrm{rt}} \mathrm{dt}+\right.
$$

$$
\left.\int_{\mathrm{T}_{1}}^{\mathrm{T}} \mathrm{I}_{2}(\mathrm{t}) \mathrm{e}^{-\mathrm{rt}} \mathrm{dt}\right]
$$

Present worth of the production cost is

$$
\mathrm{PC}=\frac{\mathrm{paD}}{\mathrm{r}}\left(1-\mathrm{e}^{-\mathrm{rT}_{1}}\right)
$$

Present worth of deterioration cost is

$$
\begin{aligned}
\mathrm{DC}= & \mathrm{c}_{2}\left[\int_{0}^{\mathrm{T}_{1}} \theta \mathrm{I}_{1}(\mathrm{t}) \mathrm{e}^{-\mathrm{rt}} \mathrm{dt}+\right. \\
& \left.\int_{\mathrm{T}_{1}}^{\mathrm{T}} \theta \mathrm{I}_{2}(\mathrm{t}) \mathrm{e}^{-\mathrm{rt}} \mathrm{dt}\right]
\end{aligned}
$$

Present worth of sales revenue is

$$
\mathrm{SR}=\frac{\mathrm{SD}}{\mathrm{r}}\left(1-\mathrm{e}^{-\mathrm{rT}}\right)
$$

Present worth of ordering cost is

$$
\mathrm{OC}=\mathrm{c}_{3}
$$

Present worth of total profit is

$$
\mathrm{TP}_{1}=\mathrm{SR}-\mathrm{PC}-\mathrm{HC}-\mathrm{DC}-\mathrm{OC}
$$

4.1.1. Remark (1): Using equation (5), we see that $\mathrm{TP}_{1}$ is the function of $\mathrm{T}_{1}$ only. Now our problem is to find the optimal value of $\mathrm{T}_{1}$ in order to maximize the total profit $\mathrm{TP}_{1}\left(\mathrm{~T}_{1}\right)$ subject to the inequality constraint $\mathrm{Q} \leq \mathrm{Q}_{0}$. Mathematically we have

$$
\begin{aligned}
& \text { Maximizing } \mathrm{TP}_{1}\left(\mathrm{~T}_{1}\right) \\
& \text { Subject to } \mathrm{Q}_{0}-\mathrm{Q} \geq 0,
\end{aligned}
$$

\subsection{Case II: $Q>Q_{0}$}

In this case production is started at time $t=0$, with zero inventory level and stopped at time $\mathrm{t}=\mathrm{T}_{2}$ when the inventory level reached the level $\mathrm{Q}$, where $\mathrm{Q}>\mathrm{Q}_{0}$. Initially the demand and the production rate are constant up to the time $t=T_{1}$ at which inventory level reaches to the level $\mathrm{Q}_{0}$ after that demand becomes stock dependent so as the production rate up to the time $t=T_{2}$. after that inventory level decreases due to the combined effect of the demand and the deterioration and reaches the zero level at the time $\mathrm{t}=\mathrm{T}$. Inventory level at any time can be described by the following differential equation and graphically represented in the figure- 2 .

$$
\begin{gathered}
I_{1}^{\prime}(t)+\theta I_{1}(t)=(a-1) D, 0 \leq t \leq T_{1}(14) \\
I_{2}^{\prime}(t)+\theta I_{2}(t)=(a-1) \alpha\left[I_{2}(t)\right]^{\beta}, \\
\quad T_{1} \leq t \leq T_{2} \\
I_{3}^{\prime}(t)+\theta I_{3}(t)=-\alpha\left[I_{3}(t)\right]^{\beta}, \\
T_{2} \leq t \leq T_{3}(16) \\
I_{4}^{\prime}(t)+\theta I_{4}(t)=-D, T_{3} \leq t \leq T
\end{gathered}
$$

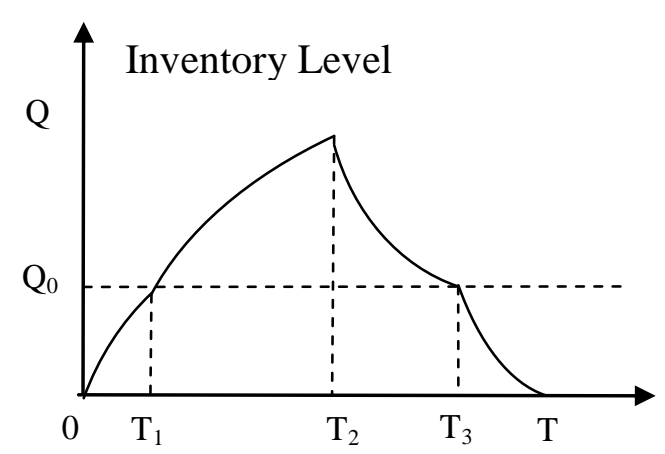

Fig 2: Case II $\left(\mathrm{Q}>\mathrm{Q}_{0}\right)$

With the boundary conditions

$\mathrm{I}_{1}(0)=0, \quad \mathrm{I}_{2}\left(\mathrm{~T}_{1}\right)=\mathrm{Q}_{0}, \mathrm{I}_{3}\left(\mathrm{~T}_{3}\right)=\mathrm{Q}_{0}$ and

$\mathrm{I}_{4}(\mathrm{~T})=0$. Solution of equations (14), (15), (16) and (17) are as follows

$$
\begin{aligned}
\mathrm{I}_{1}(\mathrm{t})= & \frac{(\mathrm{a}-1) \mathrm{D}}{\theta}\left(1-\mathrm{e}^{-\theta \mathrm{t}}\right), 0 \leq \mathrm{t} \leq \mathrm{T}_{1} \\
\mathrm{I}_{2}(\mathrm{t})= & {\left[\frac{(\mathrm{a}-1) \alpha}{\theta}+\left\{\mathrm{Q}_{0}^{(1-\beta)}-\frac{(\mathrm{a}-1) \alpha}{\theta}\right\}\right.} \\
\mathrm{I}_{3}(\mathrm{t})= & {\left[\left\{\mathrm{Q}_{0}^{(1-\beta)}+\frac{\alpha}{\theta}\right\} \mathrm{e}^{\theta(1-\beta)\left(\mathrm{T}_{3}-\mathrm{t}\right)}\right.} \\
& \left.\left.-\frac{\alpha}{\theta}\right]^{1 /(1-\beta)}, \mathrm{T}_{1}-\mathrm{t}\right) \mathrm{T}_{2} \leq \mathrm{t} \leq \mathrm{T}_{3} \\
\mathrm{I}_{4}(\mathrm{t})= & \frac{\mathrm{D}}{\theta}\left(\mathrm{e}^{\theta(\mathrm{T}-\mathrm{t})}-1\right), \mathrm{T}_{1} \leq \mathrm{t} \leq \mathrm{T}_{2}
\end{aligned}
$$

From equation (18), using the condition $\mathrm{I}_{1}\left(\mathrm{~T}_{1}\right)=\mathrm{Q}_{0}$, we have

$$
\mathrm{T}_{1}=\frac{1}{\theta} \ln \left[\frac{(\mathrm{a}-1) \mathrm{D}}{(\mathrm{a}-1) \mathrm{D}-\mathrm{Q}_{0} \theta}\right]
$$

From equation (19) and (20), using the condition $\mathrm{I}_{2}\left(\mathrm{~T}_{2}\right)=\mathrm{I}_{3}\left(\mathrm{~T}_{2}\right)$, we have

$$
\begin{aligned}
\mathrm{T}_{3}= & \frac{1}{\theta(1-\beta)} \ln \left[\frac { 1 } { ( \alpha + \theta \mathrm { Q } _ { 0 } ^ { ( 1 - \beta ) } ) } \left\{\mathrm{a} \alpha \mathrm{e}^{\theta(1-\beta) \mathrm{T}_{2}}\right.\right. \\
& \left.\left.+\left(\theta \mathrm{Q}_{0}^{(1-\beta)}-(\mathrm{a}-1) \alpha\right) \mathrm{e}^{\theta(1-\beta) \mathrm{T}_{1}}\right\}\right]
\end{aligned}
$$

From equation (21) using the condition $\mathrm{I}_{4}\left(\mathrm{~T}_{3}\right)=\mathrm{Q}_{0}$, we have 


$$
\begin{aligned}
\mathrm{T}_{4}= & \frac{1}{\theta(1-\beta)} \ln \left[\frac { 1 } { ( \alpha + \theta \mathrm { Q } _ { 0 } ^ { ( 1 - \beta ) } ) } \left\{\mathrm{a} \alpha \mathrm{e}^{\theta(1-\beta) \mathrm{T}_{2}}\right.\right. \\
& \left.\left.+\left(\theta \mathrm{Q}_{0}^{(1-\beta)}-(\mathrm{a}-1) \alpha\right) \mathrm{e}^{\theta(1-\beta) \mathrm{T}_{1}}\right\}\right]+ \\
& \frac{1}{\theta} \ln \left[1+\frac{\theta}{\alpha} \mathrm{Q}_{0}^{(1-\beta)}\right]
\end{aligned}
$$

Maximum inventory levels is

$$
\begin{aligned}
S= & I_{2}\left(T_{2}\right)=\left[\frac{(a-1) \alpha}{\theta}+\left\{Q_{0}^{(1-\beta)}-\right.\right. \\
& \left.\left.\frac{(a-1) \alpha}{\theta}\right\} e^{\theta(1-\beta)\left(T_{1}-T_{2}\right)}\right]^{1 /(1-\beta)}
\end{aligned}
$$

Present worth of the holding cost is

$$
\begin{aligned}
\mathrm{HC}= & \mathrm{c}_{1}\left[\int_{0}^{\mathrm{T}_{1}} \mathrm{I}_{1}(\mathrm{t}) \mathrm{e}^{-\mathrm{rt}} \mathrm{dt}+\int_{\mathrm{T}_{1}}^{\mathrm{T}_{2}} \mathrm{I}_{2}(\mathrm{t}) \mathrm{e}^{-\mathrm{rt}} \mathrm{dt}\right. \\
& \left.+\int_{\mathrm{T}_{2}}^{\mathrm{T}_{3}} \mathrm{I}_{3}(\mathrm{t}) \mathrm{e}^{-\mathrm{rt}} \mathrm{dt}+\int_{\mathrm{T}_{3}}^{\mathrm{T}} \mathrm{I}_{4}(\mathrm{t}) \mathrm{e}^{-\mathrm{rt}} \mathrm{dt}\right]
\end{aligned}
$$

Present worth of deterioration cost is

$$
\begin{aligned}
D C & =c_{2}\left[\int_{0}^{\mathrm{T}_{1}} \theta \mathrm{I}_{1}(\mathrm{t}) \mathrm{e}^{-\mathrm{rt}} \mathrm{dt}+\int_{\mathrm{T}_{1}}^{\mathrm{T}_{2}} \theta \mathrm{I}_{2}(\mathrm{t}) \mathrm{e}^{-\mathrm{rt}} \mathrm{dt}\right. \\
& \left.+\int_{\mathrm{T}_{2}}^{\mathrm{T}_{3}} \theta \mathrm{I}_{3}(\mathrm{t}) \mathrm{e}^{-\mathrm{rt}} \mathrm{dt}+\int_{\mathrm{T}_{3}}^{\mathrm{T}} \theta \mathrm{I}_{4}(\mathrm{t}) \mathrm{e}^{-\mathrm{rt}} \mathrm{dt}\right]
\end{aligned}
$$

Present worth of production cost is

$$
\begin{aligned}
P C= & p\left[\int_{0}^{T_{1}} a D e^{-r t} d t+\right. \\
& \left.\int_{T_{1}}^{T_{2}} a \alpha\left\{I_{2}(t)\right\}^{\beta} e^{-r t} d t\right]
\end{aligned}
$$

Present worth of sales revenue is

$$
\begin{aligned}
\mathrm{SR}= & \mathrm{s} \alpha\left[\int_{0}^{\mathrm{T}_{1}} \mathrm{De} \mathrm{e}^{-\mathrm{rt}} \mathrm{dt}+\int_{\mathrm{T}_{1}}^{\mathrm{T}_{2}}\left\{\mathrm{I}_{2}(\mathrm{t})\right\}^{\beta} \mathrm{e}^{-\mathrm{rt}} \mathrm{dt}\right. \\
& \left.+\int_{\mathrm{T}_{2}}^{\mathrm{T}_{3}}\left\{\mathrm{I}_{3}(\mathrm{t})\right\}^{\beta} \mathrm{e}^{-\mathrm{rt}} \mathrm{dt}+\int_{\mathrm{T}_{3}}^{\mathrm{T}} \mathrm{De}^{-\mathrm{rt}} \mathrm{dt}\right]
\end{aligned}
$$

Present worth of ordering cost is

$$
\mathrm{OC}=\mathrm{c}_{3}
$$

Present worth of total profit is

$$
\mathrm{TP}_{2}=\mathrm{SR}-\mathrm{PC}-\mathrm{HC}-\mathrm{DC}-\mathrm{OC}
$$

4.2.1. Remark (2): Using equation (22), (23) and (24), we see that $\mathrm{TP}_{2}$ is the function of $\mathrm{T}_{2}$ only. Now our problem is to find the optimal value of $T_{2}$ in order to maximize the total profit $\mathrm{TP}_{2}\left(\mathrm{~T}_{2}\right)$ subject to the inequality constraint $\mathrm{Q}>\mathrm{Q}_{0}$.

Mathematically we have

$$
\begin{aligned}
& \text { Maximizing } \mathrm{TP}_{2}\left(\mathrm{~T}_{2}\right) \\
& \text { Subject to } \mathrm{Q}-\mathrm{Q}_{0}>0,
\end{aligned}
$$

\section{NUMERICAL ILLUSTRATIONS}

5.1. Case I: $Q_{0} \geq Q$ :

The following numerical data are used to illustrate the model.

$\mathrm{a}=1.2, \alpha=25, \beta=0.25, \mathrm{Q}_{0}=150, \mathrm{c}_{1}=0.5, \mathrm{c}_{2}=0.4, \mathrm{c}_{3}=200$, $\mathrm{p}=5, \mathrm{~s}=9, \mathrm{~d}=0.1, \mathrm{i}=0.05, \mathrm{r}=0.05, \theta=0.01$

For the above assumed parametric values the results are obtained using GA and results are presented in Table 1. It is found that optimal cycle length $\mathrm{T}=10.66$, maximum inventory level $\mathrm{Q}=149.99$ units, production time $\mathrm{T}_{1}=8.96$ and the present value of the optimal profit is 2219.12. So at the beginning of each cycle the manufacturer produce the items at a rate $\mathrm{P}$ for the period $\mathrm{T}_{1}=8.96$. During this period inventory is built up at the rate $P-D-\theta I(t)$, and at time $t=8.96$ inventory level reaches149.99 units. At this time the manufacturer stops production and inventory depleted due to the combined effect of demand and deterioration. Inventory level reaches zero level at time $\mathrm{t}=10.66$, then production for next cycle starts.

5.2. Sensitivity analysis, Case $I: Q_{0} \geq Q$ : variation of the total profit w.r.t. different parameters and results are presented in the table 2, 3, 4 and 5 .

\subsection{Case II: $Q>Q_{0}$}

Using the same data as in case-I, results are obtained using GA and presented in Table 6.

It is found that optimal cycle length $\mathrm{T}=38.21$, maximum inventory level $\mathrm{Q}=574.38$ units, production time $\mathrm{T}_{2}=32.67$ and the present value of the optimal profit is 12813.90 . So at the beginning of each cycle the manufacturer produce the items at a rate $\mathrm{P}$ for the period $\mathrm{T}_{1}=32.67$. During this period inventory is built up and at time $\mathrm{t}=32.67$, inventory level reaches 574.38 units. At this time the manufacturer stops production and inventory depleted due to the combined effect of demand and deterioration. Inventory level reaches zero level at time $\mathrm{t}=$ 38.21 , then production for next cycle starts.

5.4. Sensitivity analysis for Case II: $Q>Q_{0}$ : variation of the total profit w.r.t. different parameters and results are presented in table 7, 8, 9 and 10.

\subsection{Observations:}

For the above parametric values optimal profit due to different production rates are obtained and presented in table 2 for case I and in table 7 for case II. From Table 1, it is observed that optimal profits decrease as production rate increases. It happens because increase in production rate, increased stock level and hence increases the holding cost. The increased holding cost dominates the profit due to increases demand hence profit decreases. From Table 7, it is observed that optimal profits increase as production rate increases. It happens because increase in production rate increases stock level and as demand is stock dependent, increased stock level increases the demand of the item, which in turn increases the profit. But increase in stock level increases the holding cost. Profit due to increased demand dominates the loss due to increased holding cost. Thus increase in the production rate increases optimal profit.

Results are obtained for the different values of demand parameters and presented in the table 3, 4 for case I and in table 8,9 for case II. It is observed that profit increases with increase in demand parameters, which agrees with reality. 
Results are obtained for the above parametric values and different values of 'resultant effect of inflation and discount rate' $r$, and presented in the table 5 for case I and in table 10 for case II. It is observed that profit decreases with increase of $r$, which agrees with reality.

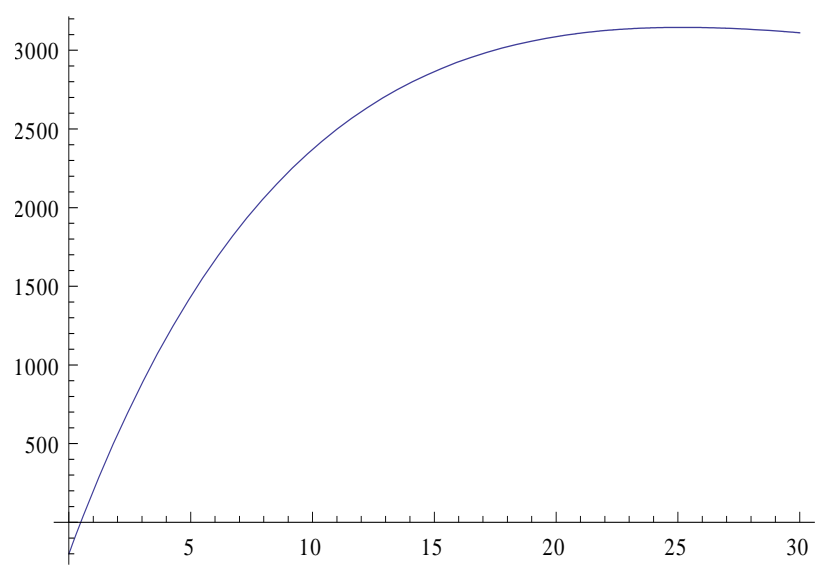

Fig 3: Total profit with respect to $T_{1}$ for Case I

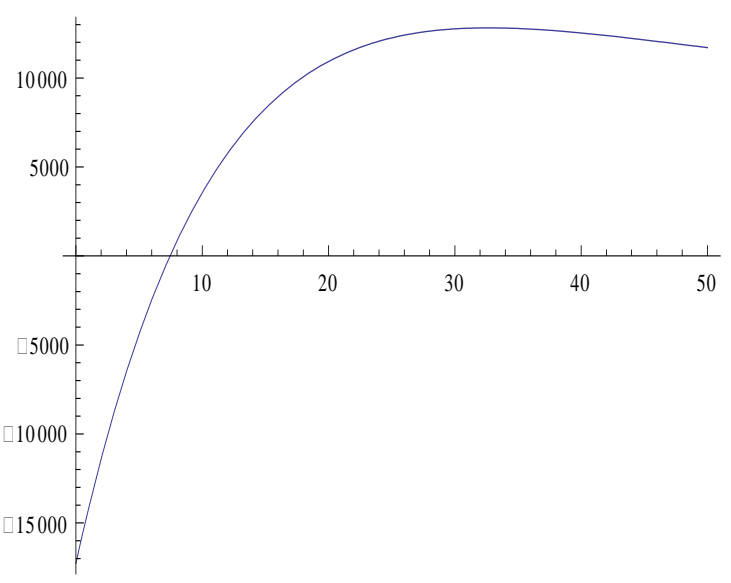

Fig 4: Total profit with respect to $T_{2}$ for Case II

\section{CONCLUSIONS AND FUTURE RESEARCH}

In this paper, an EPQ model has been considered under inflation and time discounting over an infinite horizon. Some interesting observations are presented. Demand is taken as the power form stock dependent and the production is taken as the demand dependent. In this paper we discussed the following two cases (I) $\mathrm{Q} \leq \mathrm{Q}_{0}$ and (II) $\mathrm{Q}>\mathrm{Q}_{0}$, where $\mathrm{Q}$ is the stock-level at the time production is stopped and $\mathrm{Q}_{0}$ is the fixed stock-level. Model is formulated to maximize the total profit. Also a genetic algorithm with varying population size is used to solve a production inventory model. It is found that this GA is efficient in solving the proposed inventory model. This GA can also be used to solve different decision making problems in different fields of science and technology. This inventory model can be extend incorporating price dependent demand, trade credit policy, two warehouse, etc.

Table 1: Optimal results for Case I: $\mathrm{Q}_{0} \geq \mathrm{Q}$

\begin{tabular}{cccc}
\hline $\mathrm{T}_{1}$ & $\mathrm{~T}$ & $\mathrm{Q}$ & $\mathrm{TP}_{1}\left(\mathrm{~T}_{1}\right)$ \\
\hline 8.96 & 10.66 & 149.99 & 2219.12 \\
\hline
\end{tabular}

Table 2: Present value of total profits of the model due to different production rates for Case I

\begin{tabular}{cccccccc}
\hline $\mathrm{a}$ & 1.1 & 1.3 & 1.4 & 1.5 & 1.6 & 1.7 & 1.8 \\
\hline $\mathrm{TP}_{1}$ & 3605.77 & 1639.64 & 1324.81 & 1127.46 & 992.27 & 893.89 & 819.11 \\
\hline
\end{tabular}

Table 3: Present value of total profits of the model due to different demand parameter " $\alpha$ " for Case I

\begin{tabular}{cccccccc}
\hline$\alpha$ & 21 & 22 & 23 & 24 & 26 & 27 & 28 \\
\hline $\mathrm{TP}_{1}$ & 2042.29 & 2091.09 & 2136.67 & 2179.26 & 2256.51 & 2291.65 & 2324.72 \\
\hline
\end{tabular}

Table 4: Present value of total profits of the model due to different demand parameter " $\beta$ " for Case I

\begin{tabular}{cccccccc}
\hline$\beta$ & 0.21 & 0.22 & 0.23 & 0.24 & 0.26 & 0.27 & 0.28 \\
\hline $\mathrm{TP}_{1}$ & 2014.26 & 2067.61 & 2119.55 & 2170.06 & 2266.73 & 2312.88 & 2357.57 \\
\hline
\end{tabular}

Table 5: Present value of total profits of the model due to different ' $r$ ' for Case I

\begin{tabular}{cccccccc}
\hline $\mathrm{r}$ & 0.046 & 0.047 & 0.048 & 0.049 & 0.051 & 0.052 & 0.053 \\
\hline $\mathrm{TP}_{1}$ & 2276.22 & 2261.77 & 2247.44 & 2233.23 & 2205.13 & 2191.24 & 2177.47 \\
\hline
\end{tabular}

Table 6: Optimal results for Case II: $Q>Q_{0}$

\begin{tabular}{cccccc}
\hline $\mathrm{T}_{1}$ & $\mathrm{~T}_{2}$ & $\mathrm{~T}_{3}$ & $\mathrm{~T}_{4}$ & $\mathrm{Q}$ & $\mathrm{TP}_{2}\left(\mathrm{~T}_{2}\right)$ \\
\hline 8.96 & 32.67 & 36.51 & 38.21 & 574.38 & 12813.90 \\
\hline
\end{tabular}


Table 7: Present value of total profits of the model due to different production rates for Case II

\begin{tabular}{ccccccc}
\hline $\mathrm{a}$ & 1.1 & 1.3 & 1.4 & 1.5 & 1.6 & 1.7 \\
\hline $\mathrm{TP}_{1}$ & 7127.14 & 19566.90 & 26545.10 & 33545.80 & 40504.10 & 47398.70 \\
\hline
\end{tabular}

Table 8: Present value of total profits of the model due to different demand parameter " $\alpha$ " for Case II

\begin{tabular}{ccccccc}
\hline$\alpha$ & 21 & 22 & 23 & 24 & 26 & 27 \\
\hline $\mathrm{TP}_{1}$ & 9287.83 & 10134.10 & 11004.60 & 11898.10 & 13751.00 & 14708.60 \\
\hline
\end{tabular}

Table 9: Present value of total profits of the model due to different demand parameter " $\beta$ " for Case II

\begin{tabular}{ccccccc}
\hline$\beta$ & 0.21 & 0.22 & 0.23 & 0.24 & 0.26 & 0.27 \\
\hline $\mathrm{TP}_{1}$ & 6694.48 & 7826.87 & 9188.04 & 10829.10 & 15222.20 & 18154.60 \\
\hline
\end{tabular}

Table 10: Present value of total profits of the model due to different ' $r$ ' for Case II

\begin{tabular}{ccccccc}
\hline $\mathrm{r}$ & 0.046 & 0.047 & 0.048 & 0.049 & 0.051 & 0.052 \\
\hline $\mathrm{TP}_{1}$ & 14082.10 & 13747.30 & 13424.80 & 13113.80 & 12524.40 & 12244.80 \\
\hline
\end{tabular}

\section{REFERENCE}

[1] Balkhi, T.Z., Benkherouf, L. 2004. On an inventory model for deteriorating items with stock dependent and time varying demand rates. Computers and Operations Research $31,223-240$.

[2] Datta T.K., Paul K., Pal A.K. 1998. Demand promotion by up-gradation under stock-dependent demand situation - a model. International Journal of Production Economics, 55, 31-38.

[3] Golnaz H. and Reza M. B. 2012. Using genetic algorithm for fuel consumption optimization of a natural gas transmission compressor station. International Journal of Computer Applications 43(1):1-6.

[4] Liao H.C., Tsai C-H, Su C.T. 2000. An inventory model with deteriorating items under inflation when a delay in payment is permissible, International Journal of Production Economics, 63, 207-214

[5] Mehta N.J. and Shah N.H. 2003. An inventory model for deteriorating items with exponentially increasing demand and shortages under inflation and time discounting, Investigacao Operacional, 23, 103-111.

[6] Michalewicz, Z. 1992, Genetic algorithms + data structures $=$ evolution programs. Berlin: Springer.

[7] Pareek, Sarla and Rani, Sujata. 2012. Supply chain inventory model for deteriorating items with stock dependent demand under progressive trade credit scheme. ASOR Bulletin 31(1), 23 - 35 .

[8] Pezzella, F., Morgantia, G., Ciaschettib, G. 2008, A genetic algorithm for the flexibile job-shop scheduling problem, Computers and Operations Research 35, 32023212 .
[9] Ramesh T k Babu and Nanda Dulal Jana. 2012. An optimized way for static channel allocation in mobile networks using Genetic algorithms. International Journal of Computer Applications 45(19):48-52.

[10] Singh, S. R., Singh, C., Singh, T.J. 2007. Optimal policy for decaying items with stock-dependent demand under inflation in a supply chain, International Review of Pure and Applied Mathematics, 3(2), 189-197.

[11] Singh, S. R., Kumari, R., Kumar, N. 2010. Replenishment policy for non-instantaneous deteriorating items with stock-dependent demand and partial back logging with two-storage facility under inflation. International Journal of Operations Research and Optimization, 1(1), 161-179.

[12] Singh, S. R., Singh, C. 2010. Two echelon supply chain model with imperfect production, for Weibull distribution deteriorating items under imprecise and inflationary environment. International Journal of Operations Research and Optimization, 1(1), 9-25.

[13] Singh, C. and Singh, S. R. 2011. Imperfect production process with exponential Demand rate, Weibull deterioration under inflation. International Journal of Operational Research, 12(4), 430-445.

[14] Teng, J.T. and Chang, C.T. 2005. Economic production quantity models for deteriorating items with price and stock dependent demand. Computers and Operational Research 32, 297-308.

[15] Wu, K.S., Ouyang, L.Y., and Yang, C. T. 2006. An optimal replenishment policy for non-instantaneous deteriorating items with stock-dependent demand and partial backlogging, International Journal of Production Economics, 101, 369-384 